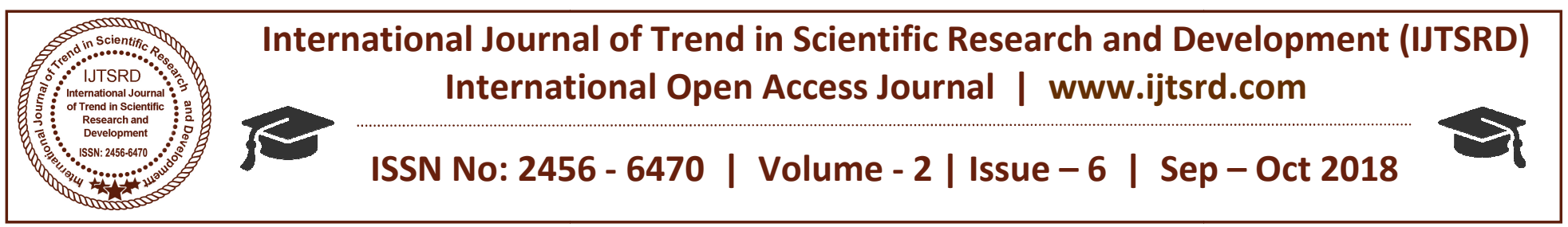

\title{
Factor Influencing Post Discharge Care of Hospitalized Children at Home Among Parents
}

\author{
Priyanka Thakur ${ }^{1}$, Dipti Y Sorte ${ }^{2}$, Sanjenbam Emon $\mathrm{Chanu}^{3}$ \\ ${ }^{1}$ M.Sc Nursing Student, ${ }^{2}$ Associate Professor, ${ }^{3}$ Assistant Professor, ${ }^{2,3}$ Child Health Nursing Department \\ Himalayan College of Nursing, Swami Rama Himalayan University, Dehradun, Uttarakhand, India
}

\begin{abstract}
Children are the future resources of the nation. Preservation of their lives will always be a priority. Today lifestyle, environmental and other factors makes the child sick for that they need special treatment. After hospitalization, they need post discharge care at home. The present study aimed to identify the factor influencing post discharge care of hospitalized children among parents. Descriptive exploratory research design was used in this study. Parents who brought their child for follow up in OPD were the samples. Semi structured questionnaires were used for collecting the data from 66 samples who were selected by purposive sampling technique. Result showed that parents faced difficulties in giving medication and in transportation. Parents were stressed and alteration in their routine work during child care. Researcher concluded that maximum participants got information about the care to be given at home from the hospital itself, but still parents got difficulty in giving care at home after discharge.
\end{abstract}

Keyword: Factors influencing, Post discharge care, children, parents

\section{INTRODUCTION}

Children are the future resources of the nation. Protecting their lives is always priority. Child health care includes birth to adolescence is crucial for parents as well as health care workers. Most of the children experience episodes of illness in their life. Visit of child to inpatient or outpatient department is a common issue of child's life. 1

The hospitalization and prolonged treatment are a hectic process for both child and parents. After completing their hospitalization, they get discharge from hospital. Hospital discharge is important transition in responsibility from inpatient team to the patient and family. Parents and guardians of hospitalized children understand the discharge plan to effective care for their child at home.2

The home care is totally delivered by any member either parents or anybody else in the family. The most of care taker are sometimes will not have either adequate information or never experienced for such a care which sometime it hampers the true care required for child. For children health protection, health promotion and health maintenance is a high priority to prevent further complications.

Discharge sick child from hospital is a routine. But transition from ward to home can be little hectic phenomena for parents and child. Post discharge care is a period offer an assistance to help and regain the fitness and function. Post discharge care targeted at their specific needs, it include support with mobility, using the toilet and bathing. If during discharge parents miss understand the instructions and advices that are given by physician. Difficulty in obtaining new prescription and also get other problem that interfere with child health outcome. 3

Parents provide special health care need to child with health care providers. Health care providers firstly place needs of the child, their family and provide training to parents of children and to assume more responsibility in their child's care. ${ }^{4}$ Child and individual family members have different experiences and the role of family is to promote successful result.5

In preparing for hospital discharge, to provide education regarding care required at home, it include medication and proper administration, monitoring for 
illness symptom and follow up appointment. 6 Parental preparation for a child's discharge from hospital for successful transitioning to care and recovery at home preparation of parents are associated with less coping difficulty in initial days of post discharge.7

\section{NEED OF THE STUDY}

As the lifestyle changes, environmental changes global warming, the morbidity and mortality among children is increasing day by day. Among those some are admitted in the hospital for the treatment and some are taking care at home.

Home care is important to the wellness of child. When a child receive care in the comfort of their own home, surrounding by familiar settings. It can make a difference for their physical and mental health and wellbeing. When reduce the time that was required to stay in the hospital, it can lower the risk of infection and communicable disease. And also benefit to family to maintain their daily activity. Early discharge also reduce the harmful effects of child separation from family 8

In early Post discharge period child need special care and emotional support from caregiver. Child need multiple and complex care after discharge from hospital to home. At home child needs assistance in some activities such as Bathing, feeding, medication. These activities are assisted by parents at home.9

A study performed by Larsson C Parents experiences of discharge readiness from a Swedish neonatal intensive care unit. The results show that the most of parents seems to be ready to go home and sufficiently supported during the first period home. Weak experiences were related to lack of time for preparation, lack of support and information, especially about the infant's food intake, breast-feeding, Ryle's tube feeding, and inadequacy of follow-up instructions after discharge. This study supports that parents who are closely involved in their infant's care at the NICU, and who stay with the infant at the NICU, are well prepared for the transition to home 10

Another study done by Sneath $\mathrm{N}$ on Discharge teaching in the NICU on "Are parents prepared? an integrative review of parent's perceptions". The results show that the data from the parent's perspective were lacking. There are limitations in the data that are available. Parents are not prepared for discharge and have unanswered questions. Parental perceptions are different from health care professionals' perceptions 11

The both study shows that there is a need of further investigation on the compliance of follow up care and reason of non-compliance of follow up care, so the researcher was decided to assess the factors influencing follow up care discharged children from Pediatric unit. Discharge should be planned well in advance so that family can be adequately informed and mother should be given all the instructions and necessary demonstration to look after the baby at home. 12

With regards to hospitalization, at the end of child hospital stay, parents are expected to assume full responsibility for their child care at home. It is important to look at discharge practices and advices that are given by the health care providers and also care given by the family members to their child based on the discharge summary. Thus, researcher wants to identify the factors influencing follow up care.

\section{OBJECTIVE}

To identify the factors influencing post discharge care of hospitalized children at home among parents.

\section{METHADOLOGY}

Descriptive exploratory research design was adopted for the study. The study was conducted at a selected hospital, Dehradun. Sixty-six (66) participants were selected as per the inclusion criteria by using purposive sampling technique. Parents who were visiting Pediatric OPD for follow up, who knows and understand Hindi language, were included. Parent whose child is sick were excluded from data collection. The data were collected by interview method using semi structured questionnaire.

Semi structured questionnaire, which was developed by the investigator and validated by experts. The tool was divided into two sections

$>$ Section A : Socio demographic variables

$>$ Section B: Semi-Structured questionnaire to identify factors influencing post discharge care. It consist of 24 items (Medication, Nutrition, Communication, Transporation, Hygiene, Rest and sleep, Finance, Stress/job environment). 
International Journal of Trend in Scientific Research and Development (IJTSRD) ISSN: 2456-6470

RESULT:-

Table 1: Factors influencing post discharge care among parents of hospitalized children

Table 1.1: Medication Factor influencing post discharge care

\begin{tabular}{|c|c|c|c|c|c|}
\hline \multirow{2}{*}{$\begin{array}{l}\text { S. } \\
\text { No. }\end{array}$} & \multirow{2}{*}{ Items } & \multicolumn{2}{|c|}{ Yes } & \multicolumn{2}{|c|}{ No } \\
\hline & & f & $\%$ & $\mathbf{f}$ & $\%$ \\
\hline 1 & $\begin{array}{l}\text { Difficulties in giving } \\
\text { medication to your } \\
\text { child }\end{array}$ & 27 & 40.9 & 39 & 59.0 \\
\hline 2 & $\begin{array}{l}\text { Forget to give } \\
\text { medication any time. }\end{array}$ & 13 & 19.7 & 53 & 80.3 \\
\hline 3 & $\begin{array}{l}\text { Child have come any } \\
\text { side effects of } \\
\text { prescribed } \\
\text { medication }\end{array}$ & 02 & 3.0 & 64 & 96.9 \\
\hline
\end{tabular}

Table no. 1.1 shows that $40.90 \%$ parents faced difficulty in giving medication and $19.69 \%$ parents forget to give medication and very few $3.03 \%$ parents reported that their child got sideneffect from prescribed medication.

Table 1.2: Nutrition factor influencing post discharge care

\begin{tabular}{|c|l|c|c|c|c|}
\hline \multicolumn{2}{|c}{\begin{tabular}{c}
\multicolumn{1}{|c|}{ S. } \\
No
\end{tabular}} & \multicolumn{2}{|c|}{ Yes } & \multicolumn{2}{|c|}{ No } \\
\cline { 2 - 6 } 1 & f & $\%$ & f & $\%$ \\
\hline 1 & $\begin{array}{l}\text { Child taking } \\
\text { adequate breast feed } \\
\text { (n=25) }\end{array}$ & 24 & 96 & $\mathbf{0 1}$ & $\mathbf{0 4}$ \\
\hline 2 & $\begin{array}{l}\text { Difficulty to feed } \\
\text { your child (n=25) }\end{array}$ & $\mathbf{0 2}$ & $\mathbf{3 . 0 3}$ & 64 & 96.96 \\
\hline 3 & $\begin{array}{l}\text { Child eat } \\
\text { homemade food }\end{array}$ & 51 & 77.27 & $\mathbf{1 5}$ & $\mathbf{2 2 . 7 2}$ \\
\hline 4 & $\begin{array}{l}\text { Child's body weight } \\
\text { is reduced }\end{array}$ & $\mathbf{3 1}$ & $\mathbf{4 6 . 9}$ & 35 & 53.0 \\
\hline
\end{tabular}

Table no. 1.2. Shows that almost all participants reported that their child was getting adequate breast feed, very few (4\%) reported that they had difficulty in feeding their child. Near to one fourth of the participants $22.72 \%$ reported that their child was not eating homemade food. More than half of the participants $53.03 \%$ reported that their child's body weight is reduced.
Table 1.3: Communication factor influencing post discharge care

\begin{tabular}{|c|c|c|c|c|c|}
\hline & & & & $(\mathrm{N}$ & $=66)$ \\
\hline S. & & & es & & No \\
\hline No & Items & $f$ & $\%$ & $F$ & $\%$ \\
\hline 1 & $\begin{array}{l}\text { Adequate knowledge } \\
\text { of treatment and care }\end{array}$ & 51 & 77.3 & 15 & 22.7 \\
\hline 2 & $\begin{array}{l}\text { Adequate } \\
\text { information about } \\
\text { discharge planning }\end{array}$ & 66 & 100 & -- & --- \\
\hline 3 & $\begin{array}{l}\text { Receive knowledge } \\
\text { about follow up care } \\
\text { adequately }\end{array}$ & 56 & 84.8 & 10 & 15.6 \\
\hline
\end{tabular}

Table 1.3 illustrated that near to one fourth $(22.72 \%)$ of parents reported that they didn't received adequate knowledge of treatment and care. But $100 \%$ of the parents got adequate information about discharged planning. $15.15 \%$ parents reported that they have not received knowledge about follow up care adequately.

Table 1.4: Transportation factor influencing post discharge care

\begin{tabular}{|c|l|c|c|c|c|}
\hline \multirow{2}{*}{$\begin{array}{c}\text { S. } \\
\text { No }\end{array}$} & \multicolumn{1}{|c|}{ Items } & \multicolumn{2}{|c|}{ Yes } & \multicolumn{2}{|c|}{ No } \\
\cline { 2 - 6 } 1 & f & $\%$ & f & $\%$ \\
\hline 1 & $\begin{array}{l}\text { Faced any difficulties } \\
\text { from hospital to home }\end{array}$ & $\mathbf{1 1}$ & $\mathbf{1 6 . 7}$ & 55 & 83.3 \\
\hline 2 & $\begin{array}{l}\text { Faced any difficulty } \\
\text { while coming from } \\
\text { home to hospital for } \\
\text { follow up }\end{array}$ & $\mathbf{1 2}$ & $\mathbf{1 8 . 2}$ & 54 & 81.8 \\
\hline
\end{tabular}

Table 1.4 Depicts that approximate $16.66 \%$ of the parents reported that they got difficulty in travelling from hospital to home As well as $18.18 \%$ parents reported that they faced difficulty in travelling for follow up visit to hospital.

\section{Table 1.5: Hygiene factor influencing post discharge care}

\begin{tabular}{|c|l|c|c|c|c|}
\hline \multicolumn{1}{|c|}{ Items } & \multicolumn{2}{|c|}{ Yes } & \multicolumn{2}{c|}{ No } \\
\cline { 3 - 6 } No & \multicolumn{1}{|c|}{ f } & $\%$ & f & $\%$ \\
\hline 1 & $\begin{array}{l}\text { Give bath to your child } \\
\text { daily }\end{array}$ & 25 & 37.8 & $\mathbf{4 1}$ & $\mathbf{6 2 . 1}$ \\
\hline 2 & $\begin{array}{l}\text { Wash hand before and } \\
\text { after caring sick child }\end{array}$ & 21 & 31.8 & $\mathbf{4 5}$ & $\mathbf{6 8 . 2}$ \\
\hline \multirow{2}{*}{3} & $\begin{array}{l}\text { Wash hand before and } \\
\text { after giving medication } \\
\text { to your child }\end{array}$ & 38 & 57.6 & $\mathbf{2 8}$ & $\mathbf{4 2 . 4}$ \\
\hline
\end{tabular}


Table 1.5 shows that majority $(62.12 \%)$ of the parents reported that they were not giving bath to their child daily. Majority $(68.18 \%)$ of the parents said that they were not washing their hand before and after touching their sick child. $42.42 \%$ of parents reported that they didn't wash their hand before and after giving medication.

\section{Table 1.6: Rest and sleep factor influencing post} discharge care

\begin{tabular}{|c|l|c|c|c|c|}
\hline \multirow{2}{*}{$\begin{array}{c}\text { S. } \\
\text { No }\end{array}$} & \multicolumn{1}{|c|}{ Items } & \multicolumn{2}{|c|}{ Yes } & \multicolumn{2}{c|}{ No } \\
\cline { 3 - 6 } 1 & $\mathrm{f}$ & $\%$ & F & $\%$ \\
\hline 1 & $\begin{array}{l}\text { Child take adequate rest } \\
\text { and sleep at home after } \\
\text { hospital discharge? }\end{array}$ & 50 & 75.7 & $\mathbf{1 6}$ & $\mathbf{2 4 . 2}$ \\
\hline 2 & $\begin{array}{l}\text { Child wakes up during } \\
\text { sleep at night because } \\
\text { of pain and discomfort? }\end{array}$ & $\mathbf{2 6}$ & $\mathbf{3 9 . 3}$ & 40 & 60.6 \\
\hline 3 & $\begin{array}{l}\text { Allow your child to } \\
\text { play? }\end{array}$ & $\mathbf{4 6}$ & 69.6 & $\mathbf{2 0}$ & $\mathbf{3 3 . 3}$ \\
\hline
\end{tabular}

Table 1.6 shows that approximately $24.2 \%$ of parent reported that their child did not take adequate rest and sleep or $39.3 \%$ parent reported that because of pain and discomfort their children wake up at night during sleep and $33.3 \%$ parents reported that they didn't allow child to play.

\section{Table 1.7: Finance factor influencing post} discharge care

\begin{tabular}{|c|c|c|c|c|c|}
\hline \multirow{2}{*}{$\begin{array}{c}\text { S. } \\
\text { No }\end{array}$} & \multirow{2}{*}{ Items } & \multicolumn{2}{|c|}{ Yes } & \multicolumn{2}{|c|}{ No } \\
\hline & & $f$ & $\%$ & $f$ & $\%$ \\
\hline 1 & $\begin{array}{l}\text { Faced any financial } \\
\text { problem during } \\
\text { hospitalization }\end{array}$ & 14 & 21.2 & 52 & 78.7 \\
\hline 2 & $\begin{array}{l}\text { Any difficulty to } \\
\text { bring your child for } \\
\text { follow up visit }\end{array}$ & 02 & 3.0 & 64 & 96.9 \\
\hline 3 & $\begin{array}{l}\text { Stop medicine to your } \\
\text { child because of } \\
\text { finance }\end{array}$ & 01 & 1.5 & 65 & 98.5 \\
\hline
\end{tabular}

Table 1.7 illustrate that $21.2 \%$ parents reported that they had faced financial problem during hospitalization. Very few $3.03 \%$ parents find difficulty to bring their child for follow up visit and hardly $1.51 \%$ parents reported that they had stop giving medicine.
Table 1.8:- Stress/ job environment factor influencing post discharge care

\begin{tabular}{|c|l|c|c|c|c|}
\hline \multicolumn{2}{|c|}{ S. } & \multicolumn{2}{|c|}{ Yes } & \multicolumn{2}{|c|}{ No } \\
\cline { 3 - 6 } No & & f & $\%$ & f & $\%$ \\
\hline 1 & $\begin{array}{l}\text { Feel any stress during } \\
\text { follow up care }\end{array}$ & $\mathbf{4 3}$ & $\mathbf{7 1 . 7}$ & 23 & 34.8 \\
\hline 2 & $\begin{array}{l}\text { Concern for care to } \\
\text { be provided to your } \\
\text { child }\end{array}$ & $\mathbf{6 6}$ & $\mathbf{1 0 0}$ & - & - \\
\hline 3 & $\begin{array}{l}\text { Disturbed your } \\
\text { routine work because } \\
\text { of your sick child }\end{array}$ & $\mathbf{3 2}$ & $\mathbf{4 8 . 5}$ & 34 & 51.5 \\
\hline
\end{tabular}

Table 1.8 shows that majority $71.66 \%$ of parents reported that feel stress during follow up care and all parents were concern for their child, Near to half $(48.48 \%)$ of parents reported that they are disturbed routine work, Difficulty in coordinate the work.

\section{DISCUSSION}

The purpose the study is to assess factor influencing post discharge care of hospitalized children

$20 \%$ of parents stated that they forget to give medication. It was contradictory to the finding by Stacee M. Lerret, Marianne E Weiss stated that parents feel stressful remembering medication and time. And Rosemary Ugwu stated that parents forget to give medicine.

Present study showed that child refuse to take medicine and vomiting after medicine similar result was supported by Rosemary Ugwu child refuse drugs and child vomited.

Present study finding shows that $15.62 \%$ of parents stated that they do not give proper attention to other children. It was supported by Stacee M. Lerret, Marianne $\mathbf{E}$ Weiss that sibling have their own schedules and it is challenging to coordinate the needs of siblings

Present study showed that parents faced disturbance in daily routine. It was supported by Julia Peres Pinto Family were suffering with routine alteration.

Present study showed that parent got difficulty in transportation. Similar findings were reported by Rosemary Ugwu, problem in transportation. And supported by Adrian HP Toh that lack of transportation. 
Present study showed that after discharge child had sleeping problem supported by Julia peres Pinto after discharge children represent insomnia.

\section{CONCLUSION}

The study demonstrated that maximum patient is came for follow up visit on time, but maximum parents got difficulty during home care. The most important factors influencing post discharge care was parent's stress during post discharge care, hygiene, child's body weight reduced, difficulty in giving medication, communication, unavailability of vehicle, cool weather and least factor parents don't stop medicine due to finance which were statistically proved.

\section{LIMITATION}

$>$ Investigator has to rely on the information given by parents.

$>$ The health status of the child as outcome variable could not be measured in the study.

$>$ Few subjects are missing as the method of data collection was interview techniques.

Sample size was small.

\section{RECOMMENDATION}

$>$ A similar study may be replicated on large sample size.

$>$ Similar study may be conducted in community area.

\section{REFERENCES}

1. Saritha. (2007).Knowledge and practice of parents regarding home management of children between 5-9 years with nephritic syndrome in TUMKUM June: $1810-20$.

2. Bansal, P., Washofsky, A., Romril, E.(2016). Parental understanding of hospital course and discharge plan; hospital pediatrics.AAP,6(8),449455

3. Health, J., Dancal, PR., Stephen, JR.(2015).Post discharge Phone calls After pediatric Hospitalization: An Observational Study.AAP, 5(5),241-48
4. MacKean, GL., Thurston, WE, Scott, CM (2005). Bridging the divide between families and health professional perspectives on family-centered care. Health Expect, 8(1), 74-85. [PMC free article] [Pub Med]

5. McCubbin, MA. (1993)Family stress theory and the development of nursing knowledge about family adaptation. . The nursing of families: Theory research education practice. Newbury Park: Sage Publications. 46-60.

6. Lerret, SM., Weiss, ME., Stendahl, GT. (2014). Transition from Hospital to Home Following Pediatric Solid Organ Transplant: Qualitative Findings of Parent Experience. Pediatric transplant,18(5),527-537 (Available at: http://www.ncbi.nlm.nih.gov/m/Pubmed/2481415 $4 /)$

7. Weiss, M., Johanson, NL., Malin, S., Jerofke, T. (2008). Readiness for discharge in parents of hospitalized children. J pediatr nurs, 23(4), 82-95

8. Pinto, j., Mandetta, M., Ribeiro, C. (2015)The family living the child recovery process after hospital discharge.REBEn,68(4),510-17

9. Line kildal Bragstand et.al. Factor Pridicting a successful post-discharge outcome for individual aged 80 years and over. Int J Integr care.2012 JanMar,12:147 available at https:/www.ncbi.nlm.nih.gov/pmc/articles/PMC34 26396)

10. Larsson C, Wagstrom U et.al. Parents experiences of discharge readiness from as Swedish neonatal intensive care unit in Sweden.PMCID,2017 April;4(2):90-95'Available at:https://www.ncbi.nlm.nih.gov/pubmed/2828666 $5 \#$

11. N Sneath; Discharge teaching in the NICU: are parents prepared? An integrative review of parents perceptions at Canada.2009 jul-aug 28(4):237-46 Available at https://www.ncbi.nlm.nih.gov/pubmed/19592365

12. S. Meharban; care of the newborn; 8th edition; CBS Publishers and distributors pvt ltd PP.590 